\title{
ST-Segment Elevation Myocardial Infarction Due to Carbon Monoxide Poisoning
}

\author{
Karbonmonoksit Zehirlenmesine Bağlı ST Segment Elevasyonlu Miyokard Enfarktüsü
}

\author{
Şeref Kerem Çorbacıoğlu, Gülşah Çıkrıkçı, Yunsur Çevik \\ Department of Emergeny Medicine, Keçiören Training and Research Hospital, Ankara, Turkey
}

\section{ABSTRACT}

Introduction: Carbon monoxide (CO) intoxications, which are often characterized by neurological and respiratory symptoms, are commonly encountered serious poisonings. However, in the literature, although cardiac complications due to poisoning are rarely mortal, conditions such as serious arrhythmias and myocardial infarction have also been reported. Cardiac evaluation and follow-up on $\mathrm{CO}$ poisoning is very important for reducing mortality.

Case Report: In the present case, we report a ST-segment elevation myocardial infarction (STEMI) believed to be triggered by CO poisoning established in a 48-year-old male patient, whose medical history was unremarkable, admitted to the emergency department due to stove poisoning and chest pain complaint.

Conclusion: Although myocardial ischemia is an expected clinical condition in CO intoxications, STEMI is rare. In general, though underlying coronary heart disease is detected on angiography of patients with STEMI due to CO poisoning, in this rare condition, coronary artery anatomy can be completely normal.

Keywords: Carbon monoxide, poisoning, myocardial infarction, angiography

Received: 20.02.2015 Accepted: 30.03.2015

Available Online Date: 12.05 .2015

\section{ÖZET}

Giriş: Karbon monoksit (CO) zehirlenmeleri sıklıkla nörolojik ve solunumsal semptomlarla seyreden yaygın olarak karşılaşılan ciddi zehirlenmelerdir. Ancak literatürde nadiren de olsa ciddi aritmiler, myokard enfarktüsü gibi zehirlenmeye bağlı mortal olabilecek kardiyak komplikasyonlar da bildirilmiştir. CO zehirlenmelerinde kardiyak değerlendirme ve takip mortalitenin azaltılması açısından oldukça önemlidir.

Olgu Sunumu: Bu yazıda, özgeçmişinde özellik olmayan ve CO zehirlenmesi sebebiyle acil servise başvuran ve göğüs ağrısı olan 48 yaşındaki erkek hastada saptanan, CO zehirlenmesinin tetiklediğini düşündüğümüz ST segment elevasyonlu myokard infarktüsü (STEMI) vakası sunulmuştur.

Sonuç: Karbon monoksit zehirlenmelerinde myokardiyal iskemi beklenen bir klinik bir durum olmakla birlikte STEMI nadir görülen bir durumdur. Genellikle karbon monoksit zehirlenmesine bağlı STEMI hastalarının anjiyografilerinde altta yatan bir koroner arter hastalığı saptansa da daha nadir durumlarda koroner anatomi tamamen normal olabilmektedir.

Anahtar Kelimeler: Karbonmonoksit, zehirlenme, myokard infarktüsü, anjiyografi

Geliş Tarihi: 20.02.2015 Kabul Tarihi: 30.03.2015

Çevrimiçi Yayın Tarihi: 12.05.2015

\section{Giriş}

Karbon monoksit (CO) zehirlenmeleri özellikle kış aylarında sık karşılaşılan ve ölümle sonuçlanabilen ciddi zehirlenmelerdir. $\mathrm{CO}$, hemoglobine oksijenden daha yüksek bir afinite ile bağlanarak dokulara giden oksijen miktarının azalmasına neden olur. Dolayısıyla beyin ve kalp gibi oksijen ihtiyacı daha fazla olan organlarda zehirlenmeye bağlı komplikasyonlar daha sık görülmektedir (1). CO zehirlenmesinde genellikle nörolojik ve solunumsal semptomlar ön planda olmasına karşın daha nadir olarak kardiyomyopati, anjina atakları, myokard enfarktüsü, aritmi, kalp yetmezliği, kardiyojenik şok ve ani ölüm gibi kardiyak komplikasyonlarda literatürde bildirilmiştir (1).

Bu vakada CO zehirlenmesinin daha nadir ancak ciddi bir komplikasyonu olarak; $C O$ zehirlenmesinin tetiklediğini düşündüğümüz ST-segment elevasyonlu miyokard enfarktüsü (STEMI) geçiren bir hasta sunulmuştur. 


\section{Olgu Sunumu}

48 yaşında bilinen bir hastalığı olmayan erkek hasta acil servisimize; soba zehirlenmesi sonrası ilçe hastanesinden CO toksisitesi şüphesiyle, CO düzeyi bakılamadığından, sevk ediliyor. Hikayesinden hastanın dış merkez acil servise baş ağrısı, bulantı ve kusma şikayetleri ile başvurduğu ancak herhangi bir göğüs ağrısı olmadığı ancak tarafımıza olası CO zehirlenmesi nedeni ile sevk edilirken ambulansta en şiddetlisi yaklaşık 20 dakika süren göğüs ağrısının olduğu öğrenildi. Illk hastane başvurusundan yaklaşık üç saat sonra acilimize başvuran hasta kritik bakı odasına kabul edildi. Illk değerlendirmesinde ilk ağrısına göre hafifleyen göğüs ağrısı haricinde ek şikayeti yoktu. Özgeçmişinde sigara kullanımı haricinde ek bir özellik yoktu. Genel durumu iyi olan hastanın bilinci açık ve glaskow koma skalası 15 idi. Hastanın vital bulguları sırasıyla kan basıncı: 148/75 mmHg, nabız: 78 atım/dk, oksijen saturasyonu: \%98, ateş: 36,7 olarak ölçüldü. Transferi boyunca maske ile oksijen alan hastaya acil servisimizde de maske ile 10 lt/dk'dan oksijen verilmeye devam edildi. Yaklaşık 3 saattir oksijen almasına rağmen ölçülen karboksihemoglobin seviyesi \%13 olarak saptandı. Hastanın ilk başvurduğu yerde çekilen elektrokardiyografisi (EKG) normal sinüs ritmindeydi. Göğüs ağrısı mevcut olan hastaya tekrar EKG çekildi ve D2, D3 ve AVF de 2 mm ST elevasyonu saptandı (Şekil 1). Mevcut bulgularla CO zehirlenmesinin tetiklediği inferior STEMI düşünüldüğü için hastaya 300 mg asetilsalisilik asit, 600 mg klopidogrel p.o ve 30 mg enoksaparin sodyum I.V. olarak verildi. Laboratuvar sonuçlarında troponin yüksekliği dışında ek bir patoloji saptanmadı (Troponin I: 130 pg/mL ND: 0-15,6). CO zehirlenmesine bağlı kardiyak etkilenme olduğu için hiperbarik oksijen (HBO) tedavisi planlandı. Ancak hastanın STEMI tanısı nedeniyle koroner anjiografi yapılmasının daha acil olduğu düşünüldü ve hasta perkutan koroner girişim için dış merkeze sevk edildi. Sevk edildiği merkezde yapılan primer perkütan anjiografisinde sağ ana koroner arterde \%90 darlık saptanan ve stent yerleştirilen hastanın EKG bulguları normalleşti ve ek klinik bir yakınması olmadı. Üç gün boyunca koroner yoğun bakımda takip edilen hasta yoğun bakım takibi sonrasında 5 seanslık HBO tedavisi planlanan hasta koroner arter hastalığı açısından da medikal tedavisi düzenlendikten sonra taburcu edildi.

Yazılı hasta onamı hastanın yakınlarından alınmıştır.

\section{Tartışma}

Karbon monoksit zehirlemelerinde oksijen sunumundaki yetersizliğe bağlı oluşan hipoksi temel semptom ve bulguların nedenidir. Çoğu vakada ön planda olan solunumsal ve nörolojiksemptomlarnedeniyle kardiyovasküler bulgular atlanabilmekte veya geç tanı alabilmektedir (2). Düşük doz maruziyetlerde myokard hasarı ve fibroz gözlenirken, yüksek doz maruziyetlerde ölümcül aritmiler görülebildiği daha önce literatürde bildirilmiştir. CO zehirlenmelerindeki kardiyotoksisitenin sadece hipoksi ile ilişkili olmadığı aynı zamanda CO gazının myosit mitokondirilerinde sitokrom oksidaz inhibisyonu yaparak direk toksik etkisi olduğu da bilinmektedir (3).

Direkt kardiyotoksik etkisine örnek olarak Jang ve ark. (4) daha önce kardiyak bir hastalığı olmayan CO zehirlenmesi sonucu acile başvuran 28 yaşındaki hastada geçici sol ventrikül disfonksiyonu saptadıkları hastayı sunmuşlardır. Benzer şekilde Çiftçi ve ark. (5) yaptıkları çalışmada hafif CO zehirlenmesi ile başvuran hastalarda başvuru anında

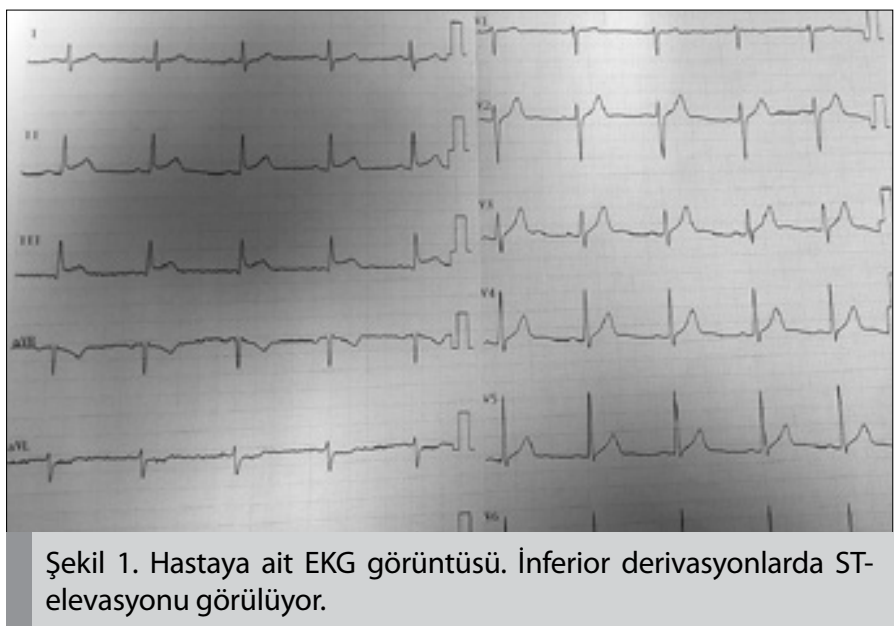

Ölçülen CO seviyelerinin sol ventrikül diyastolik fonksiyonlarındaki bozulma ile korele olduğunu göstermişlerdir.

Özellikle yüksek düzey karboksihemoglobin (COHb) saptanan hastalarda çeşitli aritmiler görülebilmektedir. Bu aritmilerin kesin nedeni tam olarak bilinmese de 2012 yılında Dallas ve ark. (6) yaptıkları çalışmada $\mathrm{CO}$ zehirlenmesinin myositlerdeki kalsiyum metobolizmasında disregülasyon ve geç sodyum kapılarında değişiklik yaparak aksiyon potansiyelinin özellikle repolarizasyon fazını uzattığını göstermişlerdir. Bunun sonucunda da aritmiye yatkınlık oluştuğunu iddia etmişlerdir.

Akilli ve ark. (7) yaptıkları çalışmada transmiyokardiyal repolarizasyon parametresi olarak inceledikleri T-pik T-son süresinin CO zehirlenmelerinde uzadığını göstermişlerdir. Ayrıca T-pik T-son süresinde uzamanın CO zehirlenmesine bağlı gelişen myokardial hasarlanma ile ilişkili olabileceğini de saptamışlardır.

Karbon monoksit zehirlenmesinde daha çok beklenen myokardial iskemi bulguları; T dalga inversiyonu, ST segment depresyonu veya EKG'de belirgin bir değişiklik olmadan kardiyak enzim yükselmesi şeklindedir. STEMI görülmesi ise daha nadirdir.

Karbon monoksit zehirlenmesinde karşılaşılan akut koroner sendrom nedeni olarak üç mekanizma tanımlanmıştır. Bunlardan ilki CO gazının ve oluşturduğu serbest radikallerin myositler üzerindeki direk toksik etkisi ile açıklanmaktadır. Ayrıca CO gazı nedeniyle oluşan genel doku hipoksisi bu hasarlanmayı artırmaktadır (8). Bu hasta grubu genellikle spesifik olmayan EKG değişikleri ve troponin yüksekliği ile seyreden ST segment elevasyonu olmayan myokard infarktüsü (NSTEMI) şeklinde karşımıza çıkmaktadır. Bahsi geçen diğer iki mekanizma ise literatürde karşılaşılan STEMI vakalarının patogenezi açıklamak içinde kullanılmıştır. Bunlardan ilki özellikle daha önceden kardiyak risk faktörleri olan kritik düzeyde olmayan koroner arter hastalığına sahip olan hastalarda CO zehirlenmesine sekonder artan oksijen ihtiyacı, kan vizkositesinde artma ve trombosit fonksiyonlarında bozulma ile kritik olmayan darlığın kritik hale gelmesi sonucu STEMI oluşmasıdır. Örneğin Dziewierz ve ark. (9) sundukları vakada COHB düzeyi \%22 olan inferior STEMI hastasının koroner anjiyografisinde distal sol anterior inen koroner arterde akut oklüzyon saptamış anjioplasti sonrasında da semptomların gerilediğini raporlamışlardır. Benzer 
şekilde Kim ve ark. (10) sundukları vakada ise CO zehirlenmesi sonrası STEMI saptadıkları hastanın anjiografisinde sağ ana koroner posterior dalında tam oklüzyonu raporlamışlardır. Anti-trombotik tedavi sonrası kontrol anjiografisinde bu tıkanıklığın kaybolduğunu belirtmişlerdir. Patogenezde suçlanan son mekanizması ise, daha önceden herhangi bir koroner arter hastalığı olmayan hastalarda CO gazının hem trombosit agregasyonu artırark hem de koroner arterlerdeki direk etkisi sonucunda vazospazm oluşturarak STEMI oluşturduğu şeklindedir (1). Buna örnek olarak McCabe ve ark. (11) sundukları vaka bulunmaktadır. Bu vakada CO zehirlenmesi sonrası STEMI tanısı alan hastada normal koroner anjiografi saptadıklarını raporlamışlardır. Bizim CO zehirlenmesi sonrası inferior STEMI tanısı koyduğumuz vakada da yapılan anjiyografide sağ ana koroner arterde kritik bir darlık saptanmıştır. Vakamızın sigara içmesi, erkek olması, ve yaşı itibariyle koroner arter risk faktörleri bulunması ve saptanan kritik düzey koroner arter darlığı bize STEMI mekanizması olarak vazospazmdan daha çok daha önceden olan kritik olmayan bir koroner darlığın CO zehirlenmesi sonrasında kritik hale geldiğini düşündürmektedir.

Kardiyak hasarlanma mekanizması ne olursa olsun CO zehirlenme hastalarında kardiyak hasarlanma saptanması HBO tedavi endikasyonları arasındadır (12). Ancak pratik uygulamalarda STEMI saptadığınız hastalarda hem anjiyografinin ön plana geçmesi hem de hastanın anjiyografi sonrasında yüksek aritmi riski nedeniyle erken dönemde $\mathrm{HBO}$ uygulamasının güvenilirliğinin ve zamanlamasının belirsiz olduğunu düşünmekteyiz. Bizim vakamız yoğun bakım sürecini tamamladıktan sonra $\mathrm{HBO}$ tedavisine alınması tercih edilmiştir.

\section{Sonuc}

Karbon monoksit zehirlenmelerinde myokardiyal iskemi beklenen bir durum olmakla birlikte STEMI nadir görülen bir durumdur. Genellikle STEMI görülen hastaların anjiyografilerinde altta yatan bir koroner hastalık saptansa da daha nadir durumlarda koroner anatomi tamamen normal olabilmektedir.

Informed Consent: Written informed consent was obtained from the patient's relative who participated in this case.

Peer-review: Externally peer-reviewed.

Author Contributions: Concept - S..K.Ç.; Design - G.Ç.; Supervision - Y.Ç.; Materials - S..K.C.; Data Collection and/or Processing - G.Ç.; Analysis and/or Interpretation - S..K.Ç.; Literature Review - G.Ç.; Writer - S..K.Ç.; Critical Review -Y.Ç.

Conflict of Interest: No conflict of interest was declared by the authors.

Financial Disclosure: The authors declared that this study has received no financial support.
Hasta Onamı: Yazılı hasta onamı hastanın yakınlarından alınmıştır.

Hakem değerlendirmesi: Dış bağımsız.

Yazar Katkıları: Fikir - Ş.K.Ç.; Tasarım - G.Ç.; Denetleme - Y.Ç.; Malzemeler S..K.Ç.; Veri toplanması ve/veya işlemesi - G.C..; Analiz ve/veya yorum - S..K.Ç.; Literatür taraması - G.Ç.; Yazıyı yazan - Ş.K.Ç.; Eleştirel Innceleme - Y.Ç.

Çıkar Çatışması: Yazarlar çıkar çatışması bildirmemişlerdir.

Finansal Destek: Yazarlar bu çalışma için finansal destek almadıklarını beyan etmişlerdir.

\section{Kaynaklar}

1. Lippi G, Rastelli G, MeschiT, Borghi L, Cervellin G. Pathophysiology, clinics, diagnosis and treatment of heart involvement in carbonmonoxide poisoning. Clin Biochem 2012; 45: 1278-85. [CrossRef]

2. Fiorista F, Casazza F, Comolatti G. Silent myocardial infarction caused by acute carbon monoxide poisoning. G Ital Cardiol 1993;23: 583-7.

3. Peers C, Steele DS. Carbonmonoxide: a vital signalling molecule and potent toxin in the myocardium. J Mol Cell Cardiol 2012; 52: 359-65. [CrossRef]

4. Jang W, Park JH. Transient Left Ventricular Systolic Dysfunction Associated with Carbon Monoxide Toxicity. J Cardiovasc Ultrasound 2010; 18: 12-5. [CrossRef]

5. Ciftçi O, Günday $M$, Calışkan M, Güllü H, Doğan R, Güven A, et al. Mild carbon monoxide poisoning impairs left ventricular diastolic function. Indian J Crit Care Med 2013; 17: 148-53. [CrossRef]

6. Dallas ML, Yang Z, Boyle JP, Boycott HE, Scragg JL, Milligan CJ, et al. Carbon monoxide induces cardiac arrhythmia via induction of the late $\mathrm{Na}+$ current. Am J Respir Crit Care Med 2012; 186: 648-56. [CrossRef]

7. Akilli NB, Akinci E, Akilli H, Dundar ZD, Koylu R, Polat M, et al. A new marker for myocardial injury in carbon monoxide poisoning: $T$ peak- $T$ end. Am J Emerg Med 2013; 31: 1651-5. [CrossRef]

8. Kao HK, Lien TC, Kou YR, Wang JH. Assessment of myocardial injury in the emergency department independently predicts the short-term poor outcome in patients with severe carbon monoxide poisoning receiving mechanical ventilation and hyperbaric oxygen therapy. Pulm Pharmacol Ther 2009; 22: 473-7. [CrossRef]

9. Dziewierz A, Ciszowski K, Gawlikowski T, Rakowski T, Kleczyński P, Surdacki A, et al. Primary Angioplasty in Patient with St-Segment Elevation Myocardial Infarction in the Setting of Intentional Carbon Monoxide Poisoning. J Emerg Med 2013; 45: 831-4. [CrossRef]

10. Kim S, Lim JH, Kim Y, Oh S, Choi WG. A case of acute carbon monoxide poisoning resulting in an ST elevation myocardial infarction. Korean circulation journal 2012; 42: 133-5. [CrossRef]

11. McCabe MJ, Weston CF, Fraser AG. Acute myocardial infarction related to smoke inhalation and myocardial bridging. Postgrad Med J 1992; 68: 758-61. [CrossRef]

12. Leach RM, Rees PJ, Wilmshurst P. Hyperbaric oxygen therapy. BMJ 1998; 317: 1140-3. [CrossRef] 